\title{
Cosmovisiones constitucionales e interrupción del embarazo
}

\author{
Paola Bergallo*
}

\section{Resumen}

El trabajo bosqueja los rasgos distintivos de dos de las cosmovisiones constitucionales que se han enfrentado en torno a la interpretación de la legislación que regula el aborto en nuestro país. Estas cosmovisiones son un constitucionalismo conservador formalista y otro de corte transformador y feminista. Contrastar estas dos perspectivas resulta útil para comprender algunas de las disidencias que separan a los juristas a uno y otro lado de los proyectos de liberalización del aborto discutidos en audiencias del Congreso de la Nación durante el 2018. La caracterización de estas posturas puede explicar además las dificultades que han rodeado la aplicación de la interpretación del artículo 86 del Código Penal según la cual este establece un sistema de causales que exige la provisión de servicios de aborto legal.

\footnotetext{
* Paola Bergallo es profesora asociada de la Escuela de Derecho de la Universidad Torcuato Di Tella, e investigadora adjunta del CONICET. Es Doctora en Derecho y Magister en Investigación Sociojurídica por la Universidad de Stanford, Magister en Leyes por la Universidad de Columbia, y abogada graduada con honores de la Universidad de Buenos Aires. Ha sido becaria, entre otros, de la Fundación Hewlett, del Consejo de Investigaciones de Noruega y del Programa de Derechos Humanos de Harvard. Ha dictado clases como profesora invitada en diversas instituciones de Argentina y el exterior, incluyendo la Universidad de Los Andes en Colombia, el ITAM en México, la Universidad Pompeu Fabra y la Autónoma de Madrid. Sus áreas de investigación incluyen el género, la salud y los derechos humanos, temas que ha abordado desde la perspectiva del derecho constitucional y los estudios sociojurídicos. Ha liderado proyectos de investigación para el Fondo de Población de Naciones Unidas (UNFPA), el Fondo Nórdico del Banco Mundial, el Centro de Derechos Reproductivos e International Planned Parenthood Federation.
} 
Palabras clave: Constitucionalismo, Constitucionalismo Conservador Formalista, Constitucionalismo Transformador, Aborto, Feminismo.

\title{
Constitutional Perspectives and the Termination of Pregnancy
}

\begin{abstract}
The paper offers a preliminary characterization of two of the constitutional perspectives confronted in the interpretation of the legal regime about abortion in our country. The paper distinguishes a conservative constitutional paradigm from a transformative and feminist constitutional approach. Contrasting these two approaches to constitutional interpretation in the context of abortion may be useful to understand the different scholarly positions represented in the debates on the prospective reform of abortion laws undertaken in the congressional hearings hosted during 2018 by Congress. The characterization of the two approaches may also contribute to explain the history of contentious implementation of the interpretation of article 86 of the Criminal Code as establishing a model of indications demanding the supply of legal abortions.
\end{abstract}

Keywords: Constitutionalism, Conservative Constitutionalism, Transformative Constitutionalism, Abortion, Feminism.

Mientras se escriben estas páginas nuestro país enfrenta un proceso de deliberación inédito sobre el status de las mujeres en nuestra sociedad. Se trata además de un proceso que podría concluir con la modernización legislativa del régimen jurídico del aborto para las personas con capacidad de gestar. Desde hace unos meses, este proceso de diálogo con epicentro en el Congreso de la Nación se extiende a cada rincón de nuestros debates públicos y privados. Como nunca antes en nuestra historia, las mujeres participamos de la deliberación disputando los sentidos del margen de determinación que da la Constitución para legislar sobre aborto a través de distintos usos del derecho penal o sin él.

El debate es resultado, entre otros, del crecimiento del movimiento de mujeres y las reivindicaciones feministas en las calles, los medios de 
comunicación y la vida pública del país. Es producto también del trabajo sostenido de iniciativas organizacionales como la Campaña por el Aborto Legal, Seguro y Gratuito así como de los esfuerzos incansables de las jóvenes, periodistas, influenciadoras y organizaciones que gestaron el movimiento Ni Una Menos y sus derivaciones. El proceso no hubiera sido posible sin la articulación de los esfuerzos transversales de las líderes políticas en el Congreso de la Nación que promovieron la invitación presidencial a abrir el debate parlamentario y luego trabajaron para ponerlo en marcha. En el primer semestre de 2018, la combinación de estas energías ha generado una deliberación legislativa con altos niveles de participación e impactos pedagógicos insospechados.

Desde el punto de vista jurídico el debate constituye además un eslabón más en el proceso de constitucionalización de los códigos de fondo iniciado con la transición democrática. Un proceso jalonado por hitos en los que durante años confrontaron abordajes constitucionales que solo coinciden en la necesidad de una lectura de las normas penales a la luz de la Constitución. El resto han sido más bien desacuerdos en los que contrastaban, entre otras, lecturas constitucionales conservadoras formalistas, de un lado, y una variedad de lecturas de cuño liberal, enfoques de derechos humanos, concepciones pragmáticas, reivindicaciones feministas y de colectivos LGBT, que en ciertas ocasiones se han combinado para moldear expresiones de un constitucionalismo transformador.

Desde 1994, estas perspectivas sobre la interpretación constitucional de la legislación sobre la interrupción del embarazo se han enfrentado en causas judiciales, sesiones legislativas y procesos regulatorios en el plano sanitario del ámbito federal y foros subnacionales. Con el tiempo, los desacuerdos jurídicos originales se han ido trasladando también a las interacciones cotidianas de la sociedad civil con el sistema de salud, las demandas organizadas del movimiento de mujeres, los colectivos LGBT y actores conservadores, hasta permear la movilización callejera. Después de años de intentos fallidos de extender la conversación constitucional sobre el tema al Congreso de la Nación, finalmente desde comienzos de 2018 la puja interpretativa en torno al derecho y el aborto se libra también en ese espacio democrático.

Leído desde 1994, este proceso jurisgenético de expansión de la argumentación constitucional sobre los derechos, la sexualidad y la reproducción, representa un ejercicio de convivencia en el disenso típico de las aspi- 
raciones de un constitucionalismo democrático o popular. ${ }^{1}$ En los últimos meses ese proceso ha generado la posibilidad de profundizar los aportes del Congreso al cambio constitucional marcado por otros hitos como las leyes que establecieron el Programa de Salud Sexual y Procreación Responsable, la exigencia de educación sexual integral, la regulación de la violencia en las relaciones interpersonales, el reconocimiento del matrimonio igualitario, o de forma más reciente la ley de identidad de género. ${ }^{2} \mathrm{El}$ debate se inserta a su vez en el largo camino que aún nos resta para alcanzar la igualdad material entre los géneros.

Casi una década atrás, Roberto Gargarella nos invitaba a pensar la Constitución para el 2020. Era difícil entonces prever la aceleración de interpretaciones favorables a la liberalización del régimen jurídico del aborto que seguirían a la decisión adoptada por entonces por el Tribunal Superior de Chubut en el caso F., A.L. ${ }^{3}$ A partir de allí, lo que habían sido debates constitucionales sencillos en casos esparcidos por algunas provincias o fallidos intentos de aprobación de una guía nacional para regular los abortos del artículo 86 del Código Penal de la Nación (CPN) comenzaron a propagarse. En esa difusión, nuestras discusiones constitucionales sobre el aborto permearon de forma gradual no solo las instituciones oficiales a las que reconocemos el poder de "decir el derecho" o instituciones jurispáticas, en el vocabulario coveriano, sino también muchos de los debates de nuestra vida comunitaria más allá de ellas. 4

1. Para una revisión de textos seminales de esta visión del constitucionalismo contemporáneo, véase Siegel, R. \& Post, R. Constitucionalismo democrático: por una reconciliación entre Constitución y pueblo. Buenos Aires, Siglo XXI, 2013, y Kramer, L. Constitucionalismo popular y control de constitucionalidad, Barcelona, Marcial Pons, 2009.

2. He desarrollado estas ideas en más profundidad en los siguientes textos: Bergallo, P., "Cambio constitucional, reproducción y derechos", en Gargarella, R., La Constitución 2020. Buenos Aires, Siglo XXI, 2011; Bergallo, P., "Las normas informales que regulan el aborto", en Cook, R., Erdman, J. \& Dickens, B. El aborto en el derecho transnacional: casos y controversias. Buenos Aires, Fondo de Cultura Económica, 2016. Bergallo, P., "Interpretando derechos: la otra legalización del aborto en América Latina", en Casas, L. \& Lawson, D., Debates y reflexiones en torno a la despenalización del aborto en Chile. Universidad Diego Portales, 2016.

3. “F., A. L. s/ Medida Autosatisfactiva”, C.S.J.N. 13.3.2012.

4. Me he referido a este fenómeno en otros trabajos como los citados supra en la nota 3. 
Las cosmovisiones constitucionales enfrentadas en esas instancias a través del último cuarto de siglo y en estos meses en particular albergan disidencias metodológicas profundas sobre la interpretación constitucional, quién tiene competencia para dirimirlas y con qué alcance puede o debe hacerlo. Estos desacuerdos atraviesan los grandes interrogantes interpretativos: qué es nuestra Constitución, cómo debería interpretársela y quién puede hacerlo; y abarcan por supuesto las disputas sustantivas sobre el sentido de las normas sobre aborto a la luz del texto constitucional. ${ }^{5}$ En definitiva, el debate sobre la constitucionalidad de la legislación del aborto ejemplifica como pocos los desacuerdos de primer y segundo orden en el plano de la interpretación constitucional.

En el primer orden, es decir, el plano de las desavenencias sobre el sentido de las normas constitucionales, estas alcanzan, por ejemplo, la identificación de los derechos relevantes del menú reconocido en la Constitución y los tratados, así como la definición de su contrapartida, las obligaciones correlativas que recaen en instituciones e individuos. Las discrepancias comprenden también la definición de las fuentes textuales y extratextuales a interpretar, los conceptos y valores morales en juego; el menú de herramientas de política pública disponible para regular la práctica; y la aceptación o no de mecanismos para balancear dimensiones de los derechos en tensión, entre otros. En el segundo orden, el plano de los desacuerdos interpretativos, las perspectivas disienten en los abordajes de la interpretación constitucional, así como en las teorías que delimitan las competencias institucionales y los márgenes de decisión de intérpretes judiciales, legislativos o administrativos.

El estudio exhaustivo de estas dimensiones del desacuerdo constitucional sobre la regulación de la interrupción del embarazo es parte de un trabajo más extenso en elaboración. Como adelanto de esa investigación, estas páginas bosquejan los rasgos distintivos de lo que propongo describir como dos de las cosmovisiones constitucionales que han protagonizado desacuerdos interpretativos sobre el régimen jurídico del aborto en nuestro país en el último cuarto de siglo. Estas cosmovisiones nuclean los ideales de una versión del constitucionalismo conservador formalista y otro que propongo denominar constitucionalismo transformador feminista. El primero,

5. Barber, S. A. \& Fleming, J. E., Constitutional Interpretation. Oxford, 2007. 
según veremos, es el resultado del proceso de laicización en nuestro entorno de discursos originalmente confesionales en la línea de lo que Julieta Lemaitre ha denominado constitucionalismo católico latinoamericano. ${ }^{6}$ La segunda cosmovisión constitucional, en cambio, combina los aportes ético-jurídicos de la tradición liberal igualitaria, un constitucionalismo de derechos humanos con énfasis en los derechos sociales, y una particular preocupación pragmática por el contexto de las normas y su funcionamiento en las instituciones democráticas que afecta las opciones de la interpretación constitucional. De esa combinación emergen, a mi juicio, los trazos de una perspectiva constitucional autóctona de cuño feminista que ubica los derechos de las personas gestantes en el centro del análisis constitucional.7

Contrastar estas dos cosmovisiones puede resultar útil para comprender las diferencias entre los discursos de algunos de los juristas a uno y otro lado

6. Lemaitre, J., "El sexo, las mujeres y el inicio de la vida en el constitucionalismo católico”, en Cook, R., Erdman, J. \& Dickens, B., op. cit. supra nota 3. Otras caracterizaciones de estas ideas pueden rastrearse en los trabajos de Juan Marco Vaggione e investigadores del Grupo de Estudios sobre Reproducción y Sexualidad de la Universidad Nacional de Córdoba. Véase, por ejemplo, Morán Faúndes, J. M. \& Peñas de Fago, M. A., "La vida como política: la iglesia católica y las concepciones científicas y legales contrarias a la legalización del aborto", en Ramón Michel, A. \& Bergallo, P., op. cit. supra nota 3, y Vaggione, J. M., "La sexualidad en el mundo post secular. El activismo religioso y los derechos sexuales y reproductivos", en Gerlero, M. S., Derecho a la Sexualidad, Buenos Aires, 2009.

7. La literatura sobre el constitucionalismo latinoamericano ha ofrecido una variedad de definiciones del constitucionalismo transformador. Entre las más divulgadas pueden verse, por ejemplo, propuestas alternativas como las articuladas en: De Sousa Santos, Boaventura, Refundación del Estado en América Latina: perspectivas desde una epistemología del Sur. Bogotá, Siglo del Hombre Editores, 2010; Ávila Santamaría, Ramiro, Acosta, A. \& Martínez, E., El neoconstitucionalismo transformador: el estado y el derecho en la Constitución de 2008. Ecuador, 2011; Von Bogdandy, A., "Ius constitutionale commune en América Latina: una mirada a un constitucionalismo transformador", en Revista Derecho del Estado, 2015, 34: 3-50. El estudio de la bibliografía argentina involucrada con esos debates es parte del proyecto más amplio en el que se insertan estas notas. En esa investigación en curso se propone un diálogo entre esas construcciones, las centradas entre ellas en temas de género, y la experiencia de constitucionalización del aborto. Estas notas preliminares escritas por invitación en un contexto deliberativo hacen un uso más informal de la idea de transformación apelando al sentido común de su voluntad reformista. 
de las audiencias celebradas en el Congreso en los últimos meses. Al mismo tiempo, comprender los desacuerdos de ambas cosmovisiones sobre la lectura constitucional de la normativa hoy vigente puede servir para explicar en parte la incertidumbre, ambivalencia y arbitrariedad que ha rodeado el funcionamiento del artículo 86 del CPN en la última década. A su turno, esta identificación de las divergencias entre un constitucionalismo conservador formalista y otro transformador y feminista podrían iluminar además la necesidad de adoptar una nueva ley que reduzca la inseguridad jurídica imperante. $^{8}$

El resto del trabajo se organiza en cuatro partes. La primera sección reconstruye de forma breve la interpretación predominante durante el siglo $\mathrm{XX}$ de las normas penales sobre aborto. La segunda sección caracteriza la estructura argumental de una variedad de constitucionalismo conservador formalista y describe algunas de las disputas jurídicas a través de las cuales esa perspectiva se desplegó con éxito hasta el primer lustro del nuevo milenio. La tercera sección introduce los principales componentes de un constitucionalismo transformador feminista que a partir de 2005 fue cosechando éxitos a través de decisiones judiciales, administrativas o legislativas hasta llegar a la apertura del debate parlamentario de este año. El trabajo concluye con una breve caracterización de las opciones que enfrenta el Congreso en el cruce de las dos cosmovisiones descriptas para abonar la propuesta de una nueva ley.

8. Desde el punto de vista metodológico, la caracterización preliminar de las cosmovisiones que ofrece este trabajo se basa en la lectura de decisiones judiciales nacionales y del derecho comparado hasta 2016, escritos en litigios en los que he colaborado entre 2005 y 2013, la revisión de publicaciones realizadas en revistas como La Ley y El derecho entre 1990-2007, el seguimiento de artículos de opinión publicados por juristas en los diarios La Nación, Página/12 y Clarín entre 1996-2017, y la participación en intercambios en las Revistas de Derecho Penal y Procesal Penal de La Ley (2010) e Infojus (2012) y tres debates sobre el proyecto de ley con otros juristas enfrentados a él en la Universidad de Buenos Aires, el Colegio Público de Abogados de la Capital Federal y la Universidad de San Andrés celebrados durante abril de 2018. No obstante, dada la enorme expansión de los discursos jurídicos a favor y en contra de la regulación del aborto que se han desarrollado (de forma oral y escrita) en los últimos meses, esta revisión no reclama exhaustividad sobre las distintas cosmovisiones enfrentadas hoy en torno al tema. La comparación que propone el trabajo es un ejercicio exploratorio basado en una indagación preliminar que se completará con una revisión sistemática de las nuevas fuentes generadas en 2018, aún en proceso. 


\section{La regulación penal del aborto y el consenso sobre la lectura constitucional}

Las normas aún vigentes que regulan el aborto en el CPN datan de 1921, cuando el Congreso aprobó un régimen que penalizaba a las mujeres y quienes colaboraran con ellas para interrumpir un embarazo. ${ }^{9}$ Esta norma punitiva incluía, sin embargo, un conjunto de circunstancias en las que el aborto no se consideraría punible. Así lo establece todavía hoy el artículo 86 del CPN, según el cual el aborto no es punible cuando es practicado por un médico con el consentimiento de la mujer encinta, en casos de peligro para la vida, peligro para la salud o violación.

Desde su aprobación y durante la mayor parte del siglo XX, esta normativa fue interpretada con éxito como estableciendo una penalización extendida del aborto y un conjunto de circunstancias de eximición de prisión poco puestas a prueba por la escasa cantidad de casos efectivamente juzgados según surge de la evidencia disponible. ${ }^{10}$ Así, se trataba de una regulación que combinaba en los libros dosis simbólicas de prohibición a partir de la amenaza penal y una permisión limitada contenida en la supuesta no aplicación de penas a las mujeres y acusados de haber participado en el delito.

Una serie de estudios recientes muestra que durante gran parte del siglo XX y hasta nuestros días la penalización efectiva fue prácticamente nula. ${ }^{11}$ En la práctica, nuestra sociedad parecía mostrar mucha tolerancia al aborto ilegal con pocas sentencias condenatorias y escasas oportunidades expresas de eximición de castigo. ${ }^{12} \mathrm{El}$ aborto se sabía ampliamente prac-

9. Véanse los artículos 85 a 88 del Código Penal de la Nación.

10. Bergallo, P., "La liberalización del aborto: contextos, modelos regulatorios y argumentos para su debate", en Bergallo, P., Aborto y Justicia Reproductiva. Buenos Aires, Editores del Puerto, 2011.

11. Sobre la historia de esta norma en la práctica, veáse Di Corleto, J., "Médicos, jueces y abortistas: Buenos Aires, 1940-1970”, en Ramón Michel, A. \& Bergallo, P., La reproducción en cuestión, Buenos Aires, Eudeba, 2018. Para datos más recientes, véase Defensoría General de la Nación, Informe: Causas penales por aborto propio en la Argentina, Buenos Aires, 2018. Disponible en: http://www.mpd.gov.ar/index.php/noticias-feed/4258segun-un-informe-de-la-defensoria-general-de-la-nacion-los-procesos-penales-por-eldelito-de-aborto-operan-en-si-mismos-como-castigo-y-las-condenas-son-la-excepcion.

12. En un trabajo anterior, basado en la revisión de sentencias publicadas en revistas ju- 
ticado de forma clandestina y eran relativamente escasos los esfuerzos de persecución penal de las mujeres que llegaban al sistema de salud en altas cifras anuales con evidencias de una complicación del aborto, complicación que no siempre podía asumirse espontánea.

Según parece, aunque sí había en algunos ámbitos denuncias y cada tanto alguna condena, no se registraban grandes números de estas últimas contra mujeres, médicos u otros partícipes, y tampoco había constancia de sanciones ejemplares o una actividad investigativa fuerte. Es más, la dogmática penal ofrecía una variedad de argumentos para rechazar el procesamiento o la persecución de mujeres denunciadas por el delito de aborto. Estos argumentos alcanzaron su máxima expresión en los votos del recordado plenario de la Cámara Correccional de la Capital Federal en el caso Natividad Frías de 1966, en el cual a partir de la idea de violación del secreto profesional o de la prohibición de autoincriminación, la mayoría de los jueces coincidían en la necesidad de desestimar las acusaciones contra la mujer que supuestamente se había sometido a una interrupción ilegal de su embarazo.

Esta regulación penal del aborto sobrevivió durante décadas hasta que, a partir de fines de los años ochenta y con más intensidad a partir de la década siguiente, surgieron una serie de discursos constitucionales tanto prohibicionistas como liberalizadores que proponían reinterpretar los mandatos del CPN a la luz de la Constitución y los tratados de derechos humanos incorporados a ella. Según veremos a continuación, a partir de 1994, estas dos cosmovisiones constitucionales libraron un conjunto de enfrentamientos que con el tiempo irían transformando el balance de las fuerzas prohibicionistas frente a las promotoras de la liberalización.

\section{Los reclamos prohibicionistas y la consolidación del constitucionalismo conservador formalista}

A partir de los años noventa un conjunto de juristas reconocidos comenzó a defender la existencia de un mandato constitucional fuerte de pro-

rídicas y datos de denuncia solicitados en la Ciudad de Buenos Aires entre 2007 y 2008 , ofrecí algunos indicios de esta caracterización. Véase, al respecto, Bergallo, P., op. cit., supra nota 10. 
tección de la vida gestacional basado en la alusión implícita al mismo en el artículo 33, y las referencias directas al amparo de la vida gestacional en el artículo 75.23, los artículos 3.1 y 4.1. de la Convención Americana de Derechos Humanos, y las declaraciones interpretativas formuladas al suscribir la Convención de Derechos del Niño -descriptas por estos académicos como parte de supuestas reservas al tratado-. ${ }^{13}$ La combinación de estas fuentes textuales serviría para fundar, según se argumentó desde entonces, una prohibición total del aborto, compatible solo con el reconocimiento de una excusa absolutoria en caso de peligro para la vida de la mujer. Esta es una de las interpretaciones jurídicas que en los últimos meses se ha traducido en el lema "salvemos las dos vidas".

Luego del fracaso en instalar una cláusula expresa sobre el comienzo de la vida en la Convención de Santa Fe, los defensores de esta interpretación cosecharon una serie de conquistas jurídicas que instalaron muchas de sus ideas como parte del sentido común constitucional sobre el aborto. Estas ideas permearon: (a) la discusión de cláusulas constitucionales a nivel provincial; (b) artículos incorporados a las leyes de salud reproductiva y educación sexual al definir la anticoncepción; (c) el debate sobre la constitucionalidad de la comercialización o la distribución en planes estatales de la anticoncepción hormonal de uso diario, la píldora del día después, el dispositivo intrauterino y las técnicas de anticoncepción quirúrgica; todas acusadas de provocar efectos abortivos; (d) el descarte de embriones en el empleo de técnicas de reproducción humana asistida; (e) el acceso al aborto en caso de anencefalia y los supuestos del artículo 86 del CPN; (f) el rechazo de la superioridad del deber de guardar secreto profesional o el argumento de la autoincriminación frente al deber de denunciar ante el conocimiento de interrupciones ilegales del embarazo; y (g) la sanción de leyes que establecían el Día del Niño por Nacer o establecían una ciudad o pueblo como jurisdicciones "pro vida". Incluso otras discusiones como la aprobación del Protocolo Facultativo de la CEDAW o la eliminación de las atenuantes del infanticidio en la etapa puerperal, por citar algunas, también se vincularon

13. En el caso F., A.L. la Corte Suprema aclaró que se trataba de una declaración interpretativa y no de una reserva a la Convención de Derechos del Niño. Para una revisión de la historia del tema, véase también Filippini, L., "Los abortos no punibles en la reforma constitucional de 1994”, en Bergallo, P., op. cit., supra nota 10. 
con las estrategias de sectores prohibicionistas para evitar el avance de interpretaciones liberales sobre el aborto.

Los foros en los que estos debates fueron expandiéndose en la década del noventa incluyeron así a nivel nacional y provincial convenciones constituyentes, legislaturas, ámbitos de la gestión pública y privada de los sistemas de salud, y con el tiempo, un número creciente de procesos judiciales en los que se buscó consolidar interpretaciones restrictivas. Pero también los espacios de producción de significados de la sociedad civil fueron terreno fértil en la expansión de la cosmovisión constitucional conservadora en torno al aborto. Por ejemplo, se escribieron numerosos libros y artículos promoviendo estas interpretaciones al tiempo que se reescribía, por ejemplo, el contenido del juramento hipocrático en universidades públicas o el texto del Código de Ética de la Academia Nacional de Medicina.

Hasta la llegada del nuevo milenio, cuando esta cosmovisión conservadora de la lectura constitucional comenzó gradualmente a ceder frente al triunfo de interpretaciones que describo en la próxima sección, sus aserciones sobre el sentido de la Constitución seguían dos tipos de estrategias: una abiertamente confesional, y otra laica basada en una importación incompleta de algunas de las herramientas argumentales del paradigma constitucional liberal. En algunos casos, además, ambos tipos de estrategias se combinaban con usos espurios del derecho comparado o fuentes pseudocientíficas, como lo testimonia, por ejemplo, el voto mayoritario del caso Portal de Belén resuelto en 2002. ${ }^{14}$ En él, la Corte Suprema de Justicia hacía referencia a encíclicas papales, fuentes incompletas del derecho internacional de los derechos humanos, párrafos tergiversados de una sentencia de la Corte del Estado de Tennessee, y la alusión a un manual de divulgación de nula autoridad científica para sustanciar su definición del comienzo de la vida. ${ }^{15}$

En su trabajo sobre constitucionalismo católico en América Latina, Julieta Lemaitre ha reconstruido algunas de las fuentes religiosas del constitucionalismo conservador de otros países de nuestra región incluyendo un

14. Monte, E., "La demanda por la liberalización del aborto en Argentina: de la politización de la sexualidad a los derechos reproductivos. Notas sobre el caso Portal de Belén", en Ramón Michel, A. \& Bergallo, P., op. cit., supra nota 3.

15. Argibay, C., "Algunos problemas actuales en el acceso a los derechos sexuales y reproductivos”, en Defensoría General de la Nación, Discriminación y Género: Las formas de la violencia, Buenos Aires, 2011. 
estudio pormenorizado de las encíclicas papales que constituyen los textos fundantes de esta tradición en su aporte al debate sobre el aborto. ${ }^{16}$ En algunas ocasiones, además, el constitucionalismo católico se ha basado en la descripción de compromisos constitucionales que rechazan la separación del Estado y la Iglesia, como las que promueven interpretaciones del artículo 2 de la Constitución argentina y otras normas de las constituciones provinciales que reconocen un status especial a la Iglesia y el culto católicos para regir los destinos de nuestras instituciones. Pero no son estas ni las experiencias más oprobiosas de manipulación de fuentes del derecho o el conocimiento científico mencionadas en el párrafo anterior -que todavía persisten, como ha podido verse en los debates en el Congreso- las que me interesa destacar aquí como parte de la cosmovisión constitucional conservadora formalista.

Prefiero más bien llamar la atención sobre los rasgos de esta cosmovisión que sobreviven a su asimilación superficial de las herramientas de un constitucionalismo liberal para promover posturas prohibicionistas en torno a la legislación sobre aborto con un enfoque textualista y mecanicista. Lemaitre y otros autores, como Juan Marco Vaggione, han destacado también hasta qué punto los sectores conservadores de nuestra región han adoptado las herramientas de una concepción laica para jugar el juego convencional de la interpretación constitucional. En efecto, si preserva algún arraigo confesional, el constitucionalismo conservador actual, en nuestro entorno lo oculta a través de un textualismo precario y selectivo desde el cual ejercita su propia cosmovisión de la interpretación constitucional "moderna".

Este textualismo opera a partir de la referencia a las normas de la Constitución citadas arriba (los artículos 33 y 75.23) y el artículo 4.1. de la Convención Americana, más supuestas reservas a la Convención de Derechos del Niño que definirían su aplicación a partir de la concepción para omitir de forma simultánea todas las referencias introducidas en la Constitución y los textos de los tratados en relación a los derechos de las mujeres. El textualismo precario funciona también a partir de la negación de la evolución y la autoridad de las fuentes del derecho nacional, comparado e internacional que interpretan todas estas normas, cuando los precedentes contravienen las lecturas conservadoras formalistas.

16. Lemaitre, J., op. cit., supra nota 7. 
La selectividad de las fuentes que integran el material pre-interpretativo sobre el que formulará su trabajo argumental esta cosmovisión constitucional trae aparejadas varias consecuencias. Para esta versión supuestamente laica del constitucionalismo conservador lo único relevante es el reconocimiento de un status de excepcionalidad constitucional y convencional a la protección de la vida biológica desde la concepción. Esta, según se esgrime, exigiría una protección absoluta y monocorde de la vida en todos sus estadios a partir de la unión de los gametos. Se rechaza así la gradualidad de la protección jurídica de la vida desde sus etapas embrionarias al tiempo que se desconoce su tensión con otros derechos de titularidad de las personas gestantes. El constitucionalismo conservador formalista descarta de esta forma cualquier tipo de ponderación o análisis de proporcionalidad que evalúe la constitucionalidad o convencionalidad del rol del derecho penal en la gestión de la política pública sobre el aborto.

De esta negación de la tensión o conflicto se sigue también el rechazo de las obligaciones regulatorias y prestacionales que podrían fundar un deber de proveer los abortos legales en el sistema de salud actual en base a la interpretación del artículo 86 del CPN y sus causales que se ha propuesto más recientemente resignificar como resultantes de la protección del derecho a la vida, la salud y la autonomía previstas en distintas normas de la Carta Magna. Para esta perspectiva constitucional, entonces, la penalización total del aborto no es una elección legislativa sino un mandato constitucional ineludible. La criminalización de la conducta durante los nueve meses no es una opción de política pública disponible como última ratio, sino una exigencia inescapable que se desprende del reconocimiento de un derecho a la vida desde la concepción y de su jerarquía sobre cualquier otra consideración valorativa. Por otro lado, en las muy marginales ocasiones en que algunos juristas, entre los que abrazan esta cosmovisión, reconocen que el aborto plantea alguna forma de tensión entre intereses y derechos en juego, se esgrime que la ponderación solo justificaría una excusa absolutoria como la que leen prevista en parte del artículo 86, inciso 1 del CPN. Justamente porque solo puede interpretarse que el artículo 86 contempla una excusa absolutoria, la lectura constitucional de dicha regla no podría imponer entonces ningún deber correlativo sobre los sistemas de salud, sus gestores y prestadores respecto de la disponibilidad de servicios de aborto legal.

No hay entonces nada más que reconocer ni ponderar una vez que hay vida humana en desarrollo, cualquiera sea su estadio de evolución. 
Poco importan desde esta perspectiva otras normas de la Constitución y los tratados de derechos humanos que reconocen derechos de titularidad de las personas gestantes. También son irrelevantes los ejercicios de ponderación que pueden asignarse al legislador democrático, refundados como lo hace la Corte Suprema argentina en el fallo F., A.L. Tampoco parecen importar los patrones convergentes de las ponderaciones realizadas en el derecho comparado en decisiones judiciales como las emitidas por tribunales con competencia constitucional como los de Estados Unidos, Canadá, Alemania, Francia, España, Colombia, México o Chile, por citar algunos. Menos aún hay para decir sobre los desarrollos del derecho internacional de los derechos humanos y los precedentes del sistema europeo o el sistema interamericano que han reconocido el carácter incremental de la protección jurídica de la vida en gestación o la necesidad de realizar un análisis de proporcionalidad ante la afectación de otros derechos reproductivos en juego. ${ }^{17}$ Menos incumben las declaraciones de Comités del sistema de monitoreo de tratados que aclaran la inexistencia de un deber de penalizar totalmente el aborto en el plano del derecho internacional de los derechos humanos. Y si alguna de estas referencias aparece en los discursos prohibicionistas mecanicistas, se trata solo de citas para marcar la lectura errada o la inaplicabilidad de la fuente en cuestión. Con ese trasfondo interpretativo, ¿qué relevancia podrían tener decisiones como las de la Corte Suprema argentina en el caso F., A.L. o los pronunciamientos concretos de foros internacionales para el país como el caso L.M.R. u otras fuentes de derecho blando internacional que abordan el tema? Pues ninguna.

En los últimos meses, esta cosmovisión constitucional es también la que ha imperado en parte de los discursos de juristas opositores a la reforma en las audiencias del Congreso, para traducirse finalmente en la suscripción del dictamen de oposición que rechazó la consideración de las distintas iniciativas de liberalización del aborto sometidas al debate parlamentario. Se trata de una cosmovisión constitucional que también ha estado presente en muchos de los discursos formulados en el recinto de Diputados la noche del

17. En este punto resulta particularmente llamativa la displicencia con la que se rechazan precedentes como Artavia Murillo vs. Costa Rica, resuelto por la Corte Americana de Derechos Humanos en 2012. 
13 de junio y se anticipa en los escritos de algunos de nuestros Senadores pocos días después.

Esta no es, cabe aclarar, la única versión de los argumentos conservadores blandidos en pos de posturas prohibicionistas. Otros juristas, cuyas posiciones no considero aquí, argumentan en cambio que la distribución de competencias institucionales que establece la Constitución no permite establecer un deber de prestar servicios de aborto legal al poder judicial, como habría hecho la Corte en F., A.L. porque disputan su jurisdicción para establecer los alcances prestacionales del derecho a la salud, por ejemplo. Otros, además, también en base a argumentos de competencia, consideran que el Congreso federal o la Corte no pueden imponer deberes prestaciones a nivel provincial. Estas concepciones conservadoras no forman parte de la versión de constitucionalismo conservador formalista que he descripto, que es más mecanicista y formalista aún. Estas concepciones conservadoras se han articulado fundamentalmente en los últimos meses de forma reactiva al debate, y todavía falta escuchar y leer más sobre ellas para poder apreciar su contrapunto con las versiones que favorecen la reforma.

\section{La perspectiva del constitucionalismo transformador y feminista}

Las posiciones prohibicionistas identificadas en la sección anterior a favor de la prohibición del aborto se han desarrollado en el plano jurídico frente a tres tipos de agendas reformistas desplegadas desde los años noventa pero con más intensidad a partir de 2005. La primera de las propuestas que favorecen una liberalización del régimen jurídico del aborto se ha enfocado en la demanda de un nuevo texto legal para regular el aborto a requerimiento restringiendo la penalización de la práctica a través de un modelo de plazos. Así lo ha promovido, por ejemplo, la Campaña por el Aborto Legal, Seguro y Gratuito desde 2005. La segunda iniciativa liberalizadora, en cambio, se ha concentrado en demandar una reinterpretación del artículo 86 del CPN entendiendo que este debe leerse como conllevando el deber de provisión de abortos legales en los sistemas de salud del país. Finalmente, un tercer conjunto de iniciativas de argumentación jurídica ha resistido los embates de interpretaciones conservadoras a través del fortalecimiento de la defensa del secreto profesional o la evidencia 
sobre abusos en casos de denuncias penales o condenas herradas por el delito de aborto. ${ }^{18}$

La historia de las propuestas de la Campaña en la promoción de una nueva ley de aborto a requerimiento en el primer trimestre combinado con causales de aborto legal a partir de la semana doce (con o sin derecho penal) es bastante conocida. ${ }^{19}$ Con los años, los proyectos de ley producidos por esta iniciativa de movilización legal fueron concitando la atención creciente de los medios de comunicación y de integrantes del Congreso que apoyaron sus reclamos hasta producir los debates abiertos este año. Durante años, cuando estos reclamos provocaban poca reacción parlamentaria, las propuestas de reinterpretación del artículo 86 del CPN también fueron avanzando a partir de decisiones judiciales en el plano nacional e internacional, y la emisión de regulaciones administrativas que pasamos a conocer como protocolos de aborto legal.

Para esta última agenda, el año 2005 marcó un punto de inflexión a partir de la visibilización de una serie de causas judiciales en las que mujeres de distintos distritos o sus representantes solicitaban el acceso a servicios de aborto legal ante situaciones de peligro para la vida o su salud, o en caso de violación. El primer caso surgido en la provincia de Buenos Aires ese año fue C.P.K.A. En él, una mujer embarazada que ya tenía dos hijos y padecía una cardiopatía severa solicitó un aborto legal por peligro para su salud por recomendación médica. Como condición para realizar la práctica, los empleados de un hospital de la provincia le exigieron autorización judicial previa, la cual fue otorgada por el Tribunal Superior de la Provincia luego de su denegación en instancias inferiores. ${ }^{20}$

A partir de entonces, casos sobre otras causales comenzaron a llegar a los tribunales de distintas provincias. En varios de estos procesos, luego de

18. En un trabajo reciente, escrito junto a Ana Cristina González Vélez, identificamos estas tres estrategias de reforma jurídica como parte de iniciativas de reconocimiento, implementación, y resistencia. Véase al respecto, González Vélez, A. C. \& Bergallo, P., "Legal mobilization and the struggle to liberalize abortion laws in Latin America" (2018, mimeo).

19. Para más información, pueden consultarse los archivos disponibles online: http:// www.abortolegal.com.ar/tag/historia/

20. La reconstrucción de esta línea de litigios puede verse en Bergallo, P., op. cit., supra notas 3 y 10. 
respuestas denegatorias fundadas en interpretaciones propias de la cosmovisión constitucional conservadora formalista, los tribunales fallaron para autorizar la realización de los abortos previstos en el artículo 86. Se fue consolidando así una reformulación del entendimiento de la regulación de no punibilidad del CPN, ahora leída en clave de causales de aborto legal fundadas en diversos valores y derechos previstos en la Constitución y los tratados de derechos humanos.

En el mismo sentido se pronunciaron a partir de 2007 las Secretarías de Salud de las Ciudades de Buenos Aires y Rosario, y de las provincias de Neuquén y Buenos Aires, al emitir protocolos de aborto no punible en los que se establecían las condiciones para la realización de los abortos legales en el sistema de salud pública de esas jurisdicciones. Idéntico camino siguieron luego las provincias de Santa Fe en 2009 y Chubut en 2010, esta última a partir de una ley provincial aprobada luego de la decisión de su máximo tribunal en el caso que hoy conocemos como F., A.L. En marzo de 2012, el fallo F., A.L. de la Corte Suprema dio un espaldarazo a estas interpretaciones que consolidaron este patrón de lecturas del artículo 86 del CPN a la luz de la Constitución y los tratados de derechos humanos. Finalmente, la exhortación de la Corte a regular la provisión de los abortos legales fue seguida de la emisión de nuevas guías sanitarias en 17 provincias y el Ministerio de Salud de la Nación. ${ }^{21}$ Con algunas variaciones en su contenido, estas nuevas guías precisaron las condiciones de realización de los abortos legales en las causales vida, salud y violación, los cuales comenzaron a realizarse con distinta previsibilidad en los subsistemas provinciales de salud. ${ }^{22}$

Antes de ofrecer una caracterización preliminar de los principales rasgos de la cosmovisión constitucional que dio lugar a estos avances interpretativos,

21. Véase al respecto, Amnistía Argentina, "El acceso al aborto en Argentina: Una deuda pendiente", 2017. Informe disponible en https://amnistia.org.ar/wp-content/uploads/ delightful-downloads/2017/o9/EL-ACCESO-AL-ABORTO-EN-ARGENTINA-ENTREGA03-FINAL.pdf

22. Cárdenas, E., López, A. \& De La Vega, L., “Aborto legal: Acceso desigualitario y criminalización selectiva”, en Centro de Estudios Legales y Sociales (CELS), Derechos Humanos en la Argentina. Informe 2017. Buenos Aires, Siglo XXI Editores, 2018. Disponible en: https://www.cels.org.ar/web/capitulos/aborto-legal-acceso-desigualitario-y-criminalizacion-selectiva/. 
vale la pena destacar algunas de las consideraciones del fallo F., A.L. y sus consecuencias. Veamos.

\section{a. Las innovaciones interpretativas del fallo F., A.L.}

Tal como lo anticipamos más arriba, las primeras formulaciones del encuadre constitucional más complejo del artículo 86 del CPN que desarrollaría la Corte Suprema en F., A.L. comenzaron a gestarse en una serie de decisiones de tribunales superiores de las provincias de Buenos Aires, ${ }^{23}$ Entre Ríos, ${ }^{24}$ Mendoza $^{25}$ y Chubut, ${ }^{26}$ adoptadas entre 2005 y 2010. Estos casos llegaron a los estrados judiciales cuando mujeres adultas, adolescentes, o sus representantes cuando estaba en juego algún tipo de discapacidad intelectual, demandaban la interrupción del embarazo por el peligro para la salud o la causal violación. En ellos, las altas cortes provinciales fallaron a favor de la constitucionalidad y convencionalidad del artículo 86 del CPN. En todos ellos, aunque las primeras instancias judiciales provinciales habían denegado la autorización para interrumpir los embarazos, las cortes superiores se pronunciaron siempre a favor de conceder la permisión del aborto, avalando la constitucionalidad del artículo 86 .

Estas decisiones interpretaron la norma del código penal, a la luz de las demandas de ponderación entre los derechos de las mujeres y la protección de la vida en gestación requeridas por el texto constitucional. ${ }^{27}$ Aunque los primeros fallos eran escuetos, la mayoría de los tribunales superiores

23. L.M.R., NN Persona por nacer. Protección. Denuncia, causa Ac. 98.830 (2006), Suprema Corte de la Provincia de Buenos Aires.

24. Defensora de PYM (en repr. de persona por nacer) s/medida cautelar de protección de persona, Superior Tribunal de Justicia de Entre Ríos, 20.9.2007, LLLitoral, noviembre de 2007, 1069 .

25. C., S. M. y otros, August 2006, Sala $1^{\text {a }}$ SCJ de Mendoza, La Ley, 2006-E, 171.

26. F.N.M., Sala "B" de la Cámara en lo Criminal de la Primera Circunscripción Judicial de la Provincia de Río Negro, 18.5.2009; F.A.L. s/ medida autosatisfactiva, Superior Tribunal de la Provincia de Chubut, 8.3.2010, Expte. 21.912-f-2010. M., Sala “A" de la Cámara de Apelaciones de la Circunscripción Judicial con asiento en Comodoro Rivadavia, Provincia de Chubut, 19.3.2010, Expte. 93/10.

27. Así lo proponía un texto pionero elaborado por Ferrante, M., "Sobre la permisividad del derecho penal argentino en casos de aborto”, en Bergallo, P., op. cit., supra nota 3. 
provinciales resolvió en este sentido. A pesar de la persistencia de algunas discrepancias, hacia fines de la primera década del siglo, comenzaba a resquebrajarse el consenso previo sobre la exigencia de una prohibición total del aborto basada en la Constitución y los tratados de derechos humanos.

El caso que originó el pronunciamiento del tribunal chubutense y luego de la Corte en F., A.L. surgió en Trelew a comienzos de 2010. Una adolescente de 16 años, violada por su padrastro, acudió entonces al sistema de salud provincial para solicitar un aborto según el artículo 86. Los profesionales de la salud que la atendieron le pidieron primero la denuncia penal de la violación y luego la autorización judicial para realizar el aborto. La adolescente recurrió entonces a la justicia provincial, donde los jueces de primera y segunda instancia rechazaron su pedido. El 8 de marzo de 2010, finalmente, el Superior Tribunal de Justicia de la provincia sostuvo la constitucionalidad del artículo 86, interpretando la causal de aborto prevista en el inciso 2 como una causal de aborto permitida a toda víctima de violación con independencia de su capacidad intelectual. Luego de ordenar la realización del aborto, ${ }^{28}$ el Tribunal exhortó además a las autoridades provinciales para que regularan el acceso a la interrupción legal. En el plazo de dos meses, la legislatura provincial respondió aprobando por unanimidad la primera ley provincial de aborto no punible del país. ${ }^{29}$

El caso fue apelado por la Asesoría Tutelar ante la Corte Suprema en representación del "no nacido". En agosto de 2010, el tribunal recibió el expediente y a partir de entonces llegaron a sus estrados numerosos amicii curiae de individuos y organizaciones de todo el país y el extranjero que acercaron sus argumentos a favor y en contra de la ILE. Finalmente, el 13 de marzo de 2012, la Corte emitió su fallo en la causa F., A.L. confirmado la decisión del tribunal de Chubut.

Para comenzar, la opinión de la mayoría de la Corte rechazó la idea de que la Constitución Nacional y los tratados de derechos humanos exigían la penalización absoluta del aborto. Los jueces entendieron que ni el artículo

28. “F., A. L. s/ Medida Autosatisfactiva”, (Expte. No 21.912-F-2010), 08/o3/2010.

29. En dos oportunidades previas, las legislaturas de la provincia de La Pampa (2007) y de la Ciudad de Buenos Aires (2008) habían considerado proyectos de legislación sobre los abortos no punibles. El proyecto de La Pampa había sido vetado por el gobernador, mientras que los proyectos debatidos en sesiones plenarias de comisiones de la Legislatura de la CABA habían terminado perdiendo estado parlamentario. 
33 ni el 75 inciso 22 de la Constitución Nacional requerían una protección absoluta del derecho a la vida. En relación a la obligación de penalizar la interrupción del embarazo, el voto mayoritario propuso evaluar uno a uno el texto de los tratados que reconocían la protección de la vida desde la concepción para concluir que esos documentos no solo no demandaban la penalización total de la práctica sino que eran compatibles tanto con la regulación de causales establecida por el artículo 86 como con un régimen de aborto a demanda, habiendo el legislador optado por el primero pero pudiendo hacerlo por el segundo.

El pronunciamiento confirmó además que los artículos 3.1 y 4.1 de la Convención Americana de Derechos Humanos eran compatibles con el modelo de regulación del aborto por causales, tal y como puede constatarse en los trabajos preparatorios para la elaboración del texto final y el hecho de que la mayoría de los países firmantes del tratado ya tenían un modelo de esas características cuando ratificaron la convención. Adicionalmente, la Corte citó la argumentación que sobre este punto había desarrollado la Comisión Interamericana de Derechos Humanos en su opinión consultiva sobre el caso Baby Boy, resuelta en $1981 .^{30}$ Los magistrados aclararon también el alcance de la "declaración interpretativa" realizada por la Argentina para la aprobación del texto final del artículo 1 de la Convención de los Derechos del Niño. Esa declaración afirma que la vida debería ser protegida desde el "momento de la concepción". ${ }^{11}$ Sin embargo, la Corte dejó en claro que este tipo de manifestaciones no tiene un status vinculante para el Estado, y por tanto, no obliga a interpretar las normas de forma restrictiva. Ello a diferencia de lo que sucede con las reservas que implican el rechazo o la no aceptación de una cláusula particular, en los términos expresos de la reserva. El tribunal entendió además que en el caso de la Convención de los Derechos del Niño, la Argentina realizó una reserva únicamente frente al artículo 21, referente a la adopción internacional, por lo que el país no estaba obligado al

30. Baby Boy, Caso 2141, Iter-Am. C.H.R. 25/OEA/ser. L./V./II.54, doc. 9 rev. 1 (1981). 31. Declaración realizada respecto del artículo 1 de la Convención de los Derechos del Niño. La República Argentina declara que el artículo debe ser interpretado entendiendo que niño, significa ser humano desde el momento de la concepción hasta los 18 años de edad. 
cumplimiento de los incisos b), c) d) y e), de dicha norma. ${ }^{32}$ La Corte también apoyó su argumentación en recomendaciones generales y específicas para la Argentina, en las cuales el Comité de los Derechos del Niño acepta la importancia de la implementación de las causales o permisos para la legalidad del aborto, en particular en casos de niñas y adolescentes. ${ }^{33}$

Luego de rechazar la interpretación conservadora formalista de cada una de las normas citadas para fundamentar la exigencia de una penalización total del aborto, la Corte pasó a detallar las diferentes provisiones constitucionales y convencionales que sustentarían la decisión legislativa por un modelo de causales como el del artículo 86. Además, la mayoría entendió que ese modelo incluía un derecho al aborto legal para todas las víctimas de violación, y no solo para las mujeres con discapacidad intelectual o psicosocial. Según la Corte, la regulación del aborto vigente ha resultado de un proceso democrático que concluyó con la adopción de un modelo de regulación aceptable, dentro del margen de las competencias del Congreso para el establecimiento de la política criminal del Estado. El tribunal mostró así su deferencia a las competencias del poder legislativo para elegir dentro de las opciones de regulación disponibles ahora reinterpretadas de forma dinámica a la luz de los compromisos constitucionales asumidos en 1994.

Finalmente, los jueces consideraron su labor intervenir para aclarar el alcance adecuado de la norma penal en el marco de la Constitución y las convenciones de derechos humanos. Estas normas exigen al legislador la opción por una alternativa regulatoria que responda a un juicio de ponderación entre el interés en la protección de la vida en gestación y el respeto de la dignidad, la igualdad y la autonomía de las mujeres. La mayoría evaluó entonces que la decisión legislativa era compatible con las provisiones constitucionales que establecen la protección de la autonomía (artículo $19 \mathrm{CN}$ ) y la igualdad (artículo $16 \mathrm{CN}$ ). El artículo 86 también se adecuaba, según los magistrados, a instrumentos de derecho internacional de los derechos

32. Ello muestra, según el voto mayoritario, que la delegación nacional tuvo intención de obligarse al cumplimiento del artículo 1ro. de dicho instrumento, en los términos en que fue aprobado por la mayoría.

33. Observaciones Finales del Comité de los Derechos del Niño, Argentina, CRC/C/ARG/ CO/3-4, del 21/o6/2010; Observaciones Finales del Comité de los Derechos del Niño: Palau. 21/02/2001. CRC/C/15/Add. 149; Observaciones Finales del Comité de los Derechos del Niño: Chad. 24/o8/1999. CRC/C/15/ Add. 107. 
humanos como la CEDAW, especialmente en cuanto aquella obliga a garantizar el pleno desarrollo de las mujeres, eliminando todas las formas de discriminación y mandando el respeto de su vida privada y familiar (artículos 2, 3, 5 y 16).34 En este sentido, el fallo cita además la Convención Interamericana para Prevenir, Sancionar y Erradicar la Violencia contra las Mujeres (Convención de Belém do Pará), que reconoce los derechos a una igual protección ante la ley, a vivir una vida libre de violencia y discriminación, y la obligación del estado de prevenir, sancionar y erradicar todos los casos de violencia contras las mujeres (artículos 4.f., 6.a, y 7). ${ }^{35}$

Por último, la Corte consideró también que todas esas normas obligaban a la interpretación de la indicación del inciso 2 del artículo 86 de forma que incluyera a todas las víctimas de violación. Para ello, citó además la recomendación, que el Comité de Derechos Humanos formuló a Perú en el $2010^{36}$ a este respecto. ${ }^{37} \mathrm{Al}$ mismo tiempo, los jueces remarcaron la importancia del reconocimiento de la dignidad de las mujeres, y la obligación de no imponerles cargas supererogatorias o heroicas. Recordaron también que el principio de legalidad impide restringir el alcance de una norma con base en una interpretación discrecional posterior.

La Corte podría haber ido más lejos, explorando argumentos más refinados sobre la autonomía, la igualdad y la dignidad de las mujeres como fundamentos de la inconstitucionalidad del modelo de indicaciones y la necesidad de adoptar un sistema de plazos abandonando la penalización del aborto al menos durante las primeras etapas de la gestación. Sin embargo, el tribunal eligió centrar su primera decisión importante sobre el tema en la defensa constitucional y convencional del modelo de indicaciones vigente. Según veremos a continuación, el tribunal fue solo más allá de los tribunales provinciales que lo habían precedido al integrar a su hermenéutica la preocupación por la implementación efectiva de la regulación de causales.

34. F., A.L., Considerando 15 .

35. Ibídem.

36. F., A.L., Considerando 12.

37. Comité para la Eliminación de todas las Formas de Discriminación contra la Mujer, Sesión 45, 12-30 Julio 2010, Observaciones Finales. CEDAW/C/ARG/CO/6; Sesión 37, 15 Enero-2 Febrero 2007, Observaciones Finales: Perú. CEDAW/C/PER/CO/6. 
En efecto, la segunda parte de la opinión de la mayoría en el caso F., A.L. reveló una sensibilidad especial al entorno del funcionamiento del artículo 86 del CPN en la práctica. Esta nueva percepción de la relevancia del contexto en el que operaba el modelo de indicaciones en nuestro país se tradujo, por un lado, en la caracterización del entorno de déficits en la aplicación del artículo 86. Por otra parte, también llevó a los jueces a considerar la dimensión institucional de los derechos para lo cual desagregaron una serie de deberes individuales e institucionales en los cuales tuvieron especialmente en cuenta el contexto de falencias descripto en primer lugar.

Según el voto mayoritario en el caso F., A.L., las deficiencias en el funcionamiento del modelo de indicaciones para el aborto configuraban una práctica contra legem, es decir, una situación ilegal. Para los jueces, esta situación ilegal resultaba del contexto de incertidumbre y desinformación existente, de la falta de claridad sobre los requisitos procedimentales de acceso a las prácticas, la falta de comprensión del funcionamiento del principio de legalidad en la regulación del aborto, y la ausencia de servicios adecuados para su realización.

Así, en primer lugar, la Corte reconoció el deber del Estado de remover todas las barreras médicas, burocráticas y judiciales que impedían el acceso a los abortos legales poniendo en riesgo la salud y la vida de las mujeres al retrasar la interrupción legal del embarazo. ${ }^{38}$ Este deber debía traducirse, para el tribunal, en la obligación del Estado de "poner a disposición, de quien solicita la práctica, las condiciones médicas e higiénicas necesarias para llevarlo a cabo de manera rápida, accesible y segura" sin imponer cargas desproporcionadas a las mujeres que soliciten interrumpir su embarazo. 39

Como su preocupación principal se enfocó en el acceso efectivo a los servicios de aborto legal, la Corte se vio obligada a precisar algunas cuestiones controvertidas en torno a la implementación del derecho al aborto: (a) el deber del Estado y todos los subsistemas de salud de proveer los servicios de aborto legal, (b) la prohibición de solicitar autorización judicial para la práctica de abortos legales, (c) la declaración jurada como único requisito para el acceso al aborto legal en caso de violencia sexual, (d) la ilegalidad de cualquier exigencia adicional a las contempladas en la norma penal, que

38. F., A.L., Considerando 24.

39. F., A.L., Considerando 25. 
puedan retrasar o impedir la práctica, (e) la necesidad de desarrollar normas procedimentales para garantizar el acceso a las interrupciones, con provisiones especiales para el caso de desacuerdo con el/la profesional frente a la solicitud de un aborto legal, y (f) la necesidad de regular el ejercicio de la objeción de conciencia por parte de profesionales de la salud para asegurar que este no comprometa o retrase el acceso de las mujeres a las prácticas solicitadas.

En el mismo sentido, la Corte recordó que tanto profesionales de la salud como funcionarios del poder judicial pueden enfrentar sanciones, penales, administrativas y civiles, por obstruir o retrasar al acceso a las interrupciones legales del embarazo. Finalmente, instó al gobierno a desarrollar campañas de información pública enfocadas especialmente en las mujeres más vulnerables para terminar con la desinformación causante de que muchas mujeres no soliciten los abortos legales y terminen en el sistema clandestino.

Interesantemente, estas consideraciones sobre la implementación del derecho al aborto se basaron también en normas de los tratados y convenciones internacionales de derechos humanos. La preocupación por el acceso a las prácticas que mostró la Corte en este fallo siguió una tendencia observada en una serie de decisiones internacionales en las que comités de monitoreo de los tratados de derechos humanos evaluaron la vulneración de derechos que implicaba la no accesibilidad de los abortos despenalizados en diversos países, entre ellos, la Argentina. Para empezar, la Corte apeló a la declaración hecha por la Asamblea General de las Naciones Unidas en 1999, en el marco de la evaluación de la agenda de la CIPD $+5 \cdot 4^{40}$ De la misma forma, citó las recomendaciones finales hechas por el Comité de Derechos Humanos de las Naciones Unidas a la Argentina en el caso L.R.M., ${ }^{41} \mathrm{y}$ por el Comité de los Derechos del Niño en 2010, en la que se exhortó a la Argentina a realizar reformas en relación con el acceso a la salud reproductiva en general, y en particular, al aborto legal. Finalmente, la Corte subrayó el riesgo de responsabilidad internacional para el país, derivado de la falta de garantía

40. United Nations, Key actions for the further implementation of the Programme of Action of the International Conference on Population and Development. New York, United Nations (A/S-21/5/Add.1), 1999.

41. L.M.R.v.Argentina (2011), UN HRC 101st Sess., UN Doc. CCPR/C/101/D/1608/2007. 
de acceso a los abortos legales, y la ausencia de reacción eficaz frente a las obstrucciones generadas por individuos, organizaciones o por autoridades del Estado, incluyendo el sistema de salud. La recepción del derecho internacional de los derechos humanos jugó entonces un papel importante en la articulación de estas nuevas preocupaciones acerca de la implementación de las normas. Las exhortaciones de la Corte, justamente se propusieron evitar o corregir situaciones de subimplementación de las normas que establecen o garantizan el derecho al aborto.

Esta relectura de las normas constitucionales que regulan los abortos se integró también con argumentos sensibles al contexto sanitario de acceso a la práctica con argumentaciones morales y de competencias basadas en la Constitución y el derecho internacional, moviéndose más allá de las afirmaciones de las primeras apelaciones de autoridad a la Constitución formuladas desde las perspectivas prohibicionistas descriptas más arriba. Desde entonces, la Corte volvió a pronunciarse en otras dos situaciones sobre el aborto. En 2013, el tribunal emitió una sentencia en la causa conocida como Profamilia, ${ }^{42}$ en la que durante el año anterior había intervenido cautelarmente ante el intento de obstrucción judicial que pretendía impedir la práctica de un aborto legal a una víctima de trata. Este caso surgió a raíz de un episodio que tomó estado público en la ciudad de Buenos Aires a finales de 2012. Una mujer que había escapado de un circuito de trata solicitó interrumpir su embarazo. Por esos días, el jefe de Gobierno de la Ciudad, Mauricio Macri, había resuelto vetar la regulación de los abortos legales aprobada por la oposición en la Legislatura. Al anunciar el veto, el entonces jefe de Gobierno declaró su voluntad de hacer cumplir la normativa administrativa que acababa de sancionar y que operaría en lugar de la ley vetada, anunciando mediáticamente detalles del aborto requerido por la víctima de trata. Ante la noticia, la organización Profamilia y un abogado representante del "por nacer", se presentaron ante la justicia de la Ciudad solicitando una medida cautelar para impedir el aborto. Aunque el juez de la Ciudad rechazó el pedido, de manera irregular la jueza civil nacional, Myriam Rustán de Estrada, concedió la cautelar violando el proceso de asignación de causas.

42. Asociación para la Defensa y Promoción de la Familia -PROFAMILIA- s/ medidas precautorias, Expte. 82.259/2012, 17 de septiembre de 2013, Corte Suprema de Justicia de la Nación. 
Dos días más tarde, la Corte intervino anulando la medida precautoria y autorizando la práctica del aborto legal. Casi un año después, el 17 de septiembre de 2013, el tribunal emitió por unanimidad su decisión exhortando a: (a) investigar el abuso de autorización para funcionar de la organización litigante, (b) evaluar el desempeño del abogado representante del "niño por nacer", y (c) investigar la potencial responsabilidad de la magistrada en el marco de la comisión de disciplina del Consejo de la Magistratura. En su breve sentencia, la Corte recordó también que las barreras descriptas generaban responsabilidad y no debían ser toleradas, como sucedía frecuentemente hasta 2012. Finalmente, en marzo de 2014, el tribunal rechazó el pedido de un conjunto de organizaciones de la sociedad civil para abrir un proceso de monitoreo del cumplimiento de la sentencia en F., A.L.

A partir de 2012, la intensificación de las discusiones constitucionales del artículo 86 del CPN ha sido tal que sería imposible rastrearlas todas aquí. Algunos informes como los elaborados por el Equipo Latinoamericano de Justicia y Género, 43 la Asociación por los Derechos Civiles, 44 Amnistía Internacional 45 o el Centro de Estudios Legales y Sociales ${ }^{46}$ ilustran mejor la eclosión de instancias de judicialización, reclamos administrativos, regulaciones y confrontaciones legales producidas luego de la intervención de la Corte Suprema en el caso F., A.L. Los estudios muestran también el registro creciente, aunque limitado, de la provisión de abortos legales en los sistemas sanitarios de algunas provincias del país. ${ }^{47}$

43. Gebruers, C. \& Gherardi, N., El aborto legal en Argentina. La justicia después de la sentencia de la Corte Suprema de Justicia en el caso F., A. L. Buenos Aires, CEDES - ELA, 2015 .

44. Asociación por los Derechos Civiles. Acceso al aborto no punible en la Argentina. Estado de situación. ADC, 2015.

45. Amnistía Argentina, op. cit., supra nota 19.

46. CELS, op. cit., supra nota 20.

47. En un ejercicio exploratorio de recopilación de los datos públicos realizado durante el 2015, encontramos por ejemplo que, según el Informe de Gestión del Programa Nacional de Salud Sexual y Procreación Responsable (en adelante, "PNSSR"), durante el año 2014, 14 provincias registraron información sobre casos de aborto no punible, entre las cuales 12 informaron haber realizado interrupciones, y 4 hicieron derivaciones a profesionales en otras provincias. Además, 3 anunciaron no tener efectores que practicaran abortos legales y 18 notificaron que contaban con al menos un efector de salud 
La falta de estadísticas necesarias para informar una política pública seria que garantice el acceso a los abortos legales y la repetición de situaciones de obstrucción como las descriptas en F., A.L. son aún parte del funcionamiento de la regulación del aborto en la práctica. No obstante, algunos estudios y cifras dispersas reflejan un cambio importante ocurrido en el transcurso de la última década en la consideración de esta normativa en el país: para el año 2015 un conjunto amplio de instituciones e individuos a través de distintas jurisdicciones ya aceptaban la provisión de abortos en las causales del artículo 86. Además, los datos indican que tanto quienes gestionan políticas públicas como quienes realizan o asisten a las mujeres registran cada vez más públicamente su intervención en casos de aborto legal. Si bien la garantía universal de acceso a los abortos legales requeriría políticas públicas más sofisticadas que este mero reconocimiento, algo ha cambiado desde el punto de vista jurídico respecto al aborto.

para realizarlas, 6 habían además mejorado sus procesos de atención, y 8 registraban limitaciones en el acceso a insumos u otro tipo de barreras en los servicios de aborto legal. Según el documento citado, 374 efectores a nivel nacional cuentan con servicios de interrupción legal y durante el 2013 se reportaron "más de 1.500 prestaciones de aborto no punibles". Disponible en: Programa Nacional de Salud Sexual y Procreación Responsable. Informe de gestión anual, año 2013. Informe provincias. Disponible en: http://tbinternet.ohchr.org/Treaties/CEDAW/Shared\%2oDocuments/ARG/INT_CEDAW_ADR_ARG_19577_O.pdf

En el nivel provincial, los datos tampoco abundan. Según la respuesta de la provincia de Tucumán a un pedido de información formulado junto a Chequeado.com y Amnistía en 2015, se han registrado solo 12 abortos legales en su territorio. En Chubut, a partir del reporte de algunos servicios de salud provinciales y el estudio de historias clínicas desde 2010, el Programa Provincial de Salud Sexual y Procreación Responsable registra: en 2010-2011, 40 abortos legales en toda la provincia; en 2012, 45; en 2013, 94; y en 2014 fueron 208. En Santa Fe, en 2011 los medios de comunicación reportaron 17 abortos legales; en 2012 fueron 14; y para 2013, solo en Rosario se habían realizado 346. Por último, en la provincia de Buenos Aires en el 2013 se realizaron 233 abortos legales. Es probable que las cifras mencionadas no reflejen todos los abortos legales realizados en el país. A su bajo nivel de sistematicidad, seguramente se sumen múltiples problemas de inconsistencias en las categorías de registro de los abortos que no se adecuan a las distinciones legales. Por otro lado, las cifras no registran los abortos legales realizados en los sistemas de obras sociales, la medicina prepaga o la contratación individual privada de servicios profesionales. 
A partir de estos cambios fragmentados y graduales, también las discusiones constitucionales han avanzado para incorporar aspectos regulatorios de los requisitos del procedimiento para realizar los abortos. De esta forma, comenzó a debatirse en distintos foros cuáles eran las exigencias constitucionales y legales respecto de cuestiones más específicas como por ejemplo: (a) la regulación del consentimiento de las adultas, las niñas y adolescentes, tuvieran o no una discapacidad intelectual, (b) los deberes de provisión de información a los distintos actores involucrados, (c) los plazos, (d) el tipo de profesionales que individualmente o en el marco de algún tipo de comité podía participar de la constatación de las causales y otras circunstancias hasta la realización del aborto, (e) las opciones terapéuticas autorizadas para realizar la ILE, (f) la necesidad de una denuncia judicial o de otro tipo en el caso de la causal violación, (g) el tipo de violencia sexual requerida, o (h) la improcedencia de la autorización judicial del aborto.

Abordar en detalle cada una de las discusiones listadas arriba de esta fase más sofisticada de lectura de las normas civiles y penales a la luz de la Constitución excede el espacio de este trabajo. Creo que este breve excurso sobre la argumentación de la Corte y las consecuencias de la sentencia es suficiente para ilustrar los rasgos de una cosmovisión constitucional contrapuesta a la versión mecanicista y conservadora con la que se había enfrentado durante años.

\section{b. Una cosmovisión constitucional transformadora y feminista}

En las reivindicaciones que dieron lugar a las interpretaciones de la Corte en F., A.L. y las que luego siguieron al trabajo por su implementación, por un lado, así como en las demandas de una reforma legislativa para establecer el aborto a requerimiento debatidas en los últimos meses en el Congreso de la Nación, es posible vislumbrar una nueva cosmovisión constitucional transformadora y feminista. En ella confluyen las herramientas propias de la interpretación ético-jurídica promovida por el constitucionalismo liberal igualitario, sumada a los recursos de un constitucionalismo social de derechos, y un enfoque pragmático de la interpretación constitucional. La combinación de estas herramientas con una impronta centrada en los derechos de las mujeres y los colectivos LGBT que proponen ampliar la categoría de sujetos gestantes para incluir, por ejemplo, a los varones trans 
con capacidad de gestar, termina de completar la identidad feminista de esta cosmovisión de vocación transformadora. $4^{4}$

Para comenzar, esta perspectiva constitucional abreva en cuatro ideas claves de la tradición constitucional liberal que incluyen, en primer lugar, el reconocimiento de la tensión o conflicto de derechos, valores y objetivos de política pública, que el derecho debe administrar al analizar la legislación vigente sobre el aborto a la luz de la Constitución. En segundo término, la tradición liberal aporta la idea de un juicio de ponderación o análisis de proporcionalidad, para efectuar el balanceo entre los derechos, valores y objetivos de política en juego. En tercer lugar, esta concepción de la interpretación constitucional contribuye alguna visión del grado de determinación que la Constitución ha previsto para esa ponderación junto a una definición de las competencias institucionales de los distintos poderes para adoptar decisiones legislativas o regulatorias. Todo ello una vez aceptado algún margen de indeterminación para el poder legislativo democrático, por supuesto. Este aparato argumental se articula además con los aportes en materia de políticas públicas y los recursos de la argumentación ético-jurídica provenientes de la filosofía moral y la ética feminista para definir el contenido de principios y valores.

Estas herramientas argumentales de la tradición liberal se han desarrollado en numerosos textos doctrinarios ${ }^{49}$ pero fueron adquiriendo con-

48. El proyecto de investigación más amplio al que me he referido en la introducción incluye un estudio más detallado de las contribuciones feministas al debate constitucional sobre la regulación del aborto en nuestro entorno. A título de ejemplo, estas ideas han sido articuladas en trabajos pioneros como los de Chiarotti, S., García Jurado, M. \& G. Schuster, "El embarazo forzado y el aborto terapéutico en el marco de los derechos humanos", en Foro por los Derechos Reproductivos. Buenos Aires, Foro por los Derechos Reproductivos, 1997; Chiarotti, S., "El aborto en el marco de los derechos humanos. La situación en Argentina”, en Checa, S., Realidades y coyunturas del aborto: entre el derecho y la necesidad, Buenos Aires, Paidós, 2006; y Faerman, R., "Algunos debates constitucionales sobre el aborto”, en Gargarella, R., Teoría y crítica del derecho constitucional, Buenos Aires, Abeledo-Perrot, 2009. Pueden verse también los artículos incluidos en las compilaciones mencionadas supra notas 3 y 10. Un estudio sistemático de esta literatura es parte del trabajo en progreso.

49. Para esa formulación en el derecho argentino, pueden verse trabajos pioneros como los de Nino, C., "Algunas reflexiones sobre el tratamiento legal del aborto y la eutanasia", en Bergallo, P., op. cit., supra nota 10; y Farrell, M., La ética del aborto y la eutanasia, Buenos Aires, Abeledo Perrot, 1993. 
senso a través de las decisiones sobre aborto adoptadas en importantes sentencias constitucionales del derecho comparado, en las que los tribunales debieron pronunciarse sobre la constitucionalidad de reformas legislativas como las que a partir de la década del setenta se sucedieron en la mayoría de los países centrales..$^{\circ}$ En los desarrollos de sentencias como las emitidas por la Corte Constitucional de Colombia a partir de 2006 y en las producidas en Argentina en los casos de aborto mencionados más arriba, este esquema argumental se ha combinado a su turno con la referencia a las normas y precedentes del derecho internacional de los derechos humanos y los riesgos de responsabilidad internacional que su desafío implicaba para el país.

Otro de los recursos centrales de esta cosmovisión constitucional es el relacionado con su fundamentación en el reconocimiento de un derecho a la salud emergente de nuestro constitucionalismo social; ${ }^{51}$ fundamentación reforzada también por previsiones de los tratados de derechos humanos como el Pacto Internacional de Derechos Económicos, Sociales y Culturales. El influjo de esta dimensión de nuestro constitucionalismo puede verse, por ejemplo, en las referencias de la Corte Suprema a la exhortación a garantizar la provisión de servicios de los abortos legales en el sistema público de salud, y en la tarea desplegada por las jurisdicciones subnacionales que con el tiempo desarrollaron, aunque con limitaciones, protocolos regulando esos mismos servicios.

Por otra parte, la impronta pragmática de esta cosmovisión puede leerse, según he defendido en otro texto, $5^{2}$ en su preocupación permanente en la argumentación por el funcionamiento de las normas "en acción" y sus reinterpretaciones en la práctica y los diseños institucionales de los sistemas de justicia y salud reales. En efecto, tanto en los reclamos judiciales de acceso a abortos no punibles, como en los debates para la consideración de

50. Para una revisión de algunas de las decisiones más importantes en este sentido puede verse Rubio Marín, R., "Transferencias jurídicas sobre mujeres y fetos: un viaje del constitucionalismo del aborto alemán al portugués”, en Ramón Michel, A. \& Bergallo, P., op. cit., supra nota 3; Siegel, R., "La constitucionalización del aborto", en Cook, R., Erdman, J. \& Dickens, B., op. cit., supra nota 3.

51. Para una descripción más completa del constitucionalismo de derechos sociales, véase Brinks, D. \& Gauri, V., "Social rights constitutionalism: Negotiating the tensión between the universal and the particular", en Annual Review of Law and Social Science 2015, 11:1, 289. 52. Véase en este punto, Bergallo, P. en Casas, L. \& Lawson, D., op. cit., supra nota 3. 
una nueva ley de plazos, esta cosmovisión constitucional ha enfatizado, en primer lugar, los límites del derecho "en acción” y la distancia que lo separa de las promesas "en los libros". Así ha quedado claro en las referencias a ambivalencia de las políticas de persecución penal al tiempo ineficaces y arbitrarias, así como en la evidencia sobre las restricciones de contexto resultantes de las prácticas contra legem, los vallados y obstáculos burocráticos impuestos para acceder a los abortos del artículo 86 del CPN. Estos vallados fueron especialmente tenidos en cuenta por la Corte Suprema en el caso F., A.L., y su persistencia, sumada a la desidia, en el desarrollo de una política pública de acceso universal a servicios de aborto legal, han sido referidas durante los debates parlamentarios recientes como parte de la evidencia que apoya la reforma. En segundo lugar, la preocupación pragmática se ha traducido en la inquietud por las dimensiones regulatorias y de política pública involucradas en el funcionamiento de la provisión de servicios de salud para acceder al aborto.

Finalmente, la combinación original de estas herramientas interpretativas sumada al foco en la fundamentación de las distintas estrategias en una demanda de protección de los derechos a la dignidad, autonomía e igualdad de las mujeres y las personas gestantes, en general, termina de darle forma a una cosmovisión constitucional transformadora y feminista comprometida con la liberalización de la legislación sobre aborto. ${ }^{53}$ He allí la novedad.

\section{A modo de conclusión}

Las páginas anteriores reconstruyen a grandes trazos dos de las cosmovisiones de la interpretación constitucional que en los últimos meses debaten para definir los destinos de la regulación del aborto en nuestro país. No son las únicas perspectivas involucradas en la discusión y lo que he presentado es, por ahora, solo un bosquejo preliminar de ambas posiciones.

En ese bosquejo, he reconstruido a un lado de la contienda la presencia de voces de un constitucionalismo conservador formalista que insisten en una protección constitucional de la vida en gestación absoluta, monocorde y

53. En un trabajo en proceso ofrezco una elaboración mayor de la caracterización feminista de esta perspectiva constitucional transformadora que aquí presento solo de forma esquemática. 
constante. Desde esta perspectiva se defiende también la necesidad de continuar empleando el derecho penal, aunque no necesariamente la política criminal contra las mujeres, para limitar una práctica que se entiende aberrante. Aunque sus detractores no siempre lo aceptan, se trata de una práctica que asimilan al homicidio de la persona nacida. En esta mirada formalista de la interpretación, persisten los discursos en que las personas gestantes y sus derechos no aparecen, pero también los relatos en los que se omiten o disputan los desarrollos del derecho nacional e internacional sobre la permisibilidad de la legislación vigente. Estas perspectivas no parecen afligirse frente a las experiencias y los sufrimientos de las personas gestantes. Tampoco preocupa la inseguridad jurídica que generan los cambios interpretativos de los últimos quince años en relación al artículo 86 del CPN y las ambigüedades de su implementación en la oferta de servicios de aborto legal a través del país. En definitiva, son pocas las novedades argumentales desarrolladas por esta cosmovisión desde sus primeras articulaciones allá por 1994.

Según propuse en estas páginas, del otro lado de la contienda asistimos al desarrollo de una cosmovisión constitucional transformadora y feminista puesta en marcha tanto a través de demandas de implementación de las normas vigentes como de reivindicaciones de su reforma legislativa. Esta visión de la interpretación constitucional se define como feminista por su foco en el reconocimiento de un lugar central a los derechos de las mujeres y las personas gestantes, en general, y por su estilo experimental al combinar herramientas de la interpretación ético-jurídica de la tradición liberal con propuestas de un constitucionalismo social de derechos, los aportes del derecho internacional de los derechos humanos, y perspectivas pragmáticas sobre la relevancia del contexto y el funcionamiento de las normas en acción. Otro rasgo feminista y pragmático de esta cosmovisión puede deducirse de su vocación pedagógica observable en las diferentes instancias en las que se ha trabajado en pos de la transformación de las conciencias legales sobre la legislación vigente y su reforma.

A diferencia del constitucionalismo conservador formalista, para esta visión de la interpretación constitucional la opción de la penalización total del aborto está claramente fuera del marco de las alternativas abiertas al poder legislativo hoy pero también queda fuera de la interpretación aceptable de las normas aprobadas en 1921. Pero además, en 2018, para esta perspectiva el margen de opciones liberalizadoras no puede incorporar con el mismo alcance la posibilidad de un nuevo sistema de causales frente a la 
opción de otro de plazos (con o sin derecho penal). Eso, porque para esta cosmovisión la reformulación del compromiso legislativo con un modelo de causales de aborto legal representa una opción por un status quo incierto e injusto desde la perspectiva de los derechos de las personas gestantes. En ese status quo, el modelo de causales del artículo 86 reinterpretado por jueces y autoridades sanitarias del país desde el 2005 no ha logrado garantizar el acceso a servicios en la práctica de un contexto anómico de incerteza, resistencias y ambivalencias políticas sobre las normas realmente válidas. En ese entorno no se ha podido diseñar una política universal de disponibilidad, accesibilidad y adaptabilidad a los abortos legales que aplicara los estándares de interpretación previstos en el fallo F.,A.L. o los protocolos de aborto legal sancionados a partir de 2007.

Esa política de garantía de servicios de aborto legal debería haber logrado:

(a) La generación de un registro centralizado de las consultas médicas recibidas, y los abortos legales realizados en los distintos sistemas de recolección de datos sanitarios existentes (i.e. el CIE y el SIP, por ejemplo).

(b) El reconocimiento de un status formal para los protocolos de aborto legal y su aprobación en todas las jurisdicciones del país para la aplicación a todos los subsistemas de salud, públicos y contributivos.

(c) Una política de recursos humanos capacitados y territorialmente bien distribuidos para garantizar la provisión de servicios de aborto legal, que contuviera además una política expresa para la gestión de objetores de conciencia.

(d) Un menú amplio y completo de alternativas terapéuticas aprobadas debidamente y disponibles para el aborto legal, incluyendo la AMEU, el Misoprostol, la Mifepristona, y servicios profesionales para el manejo del dolor, por ejemplo.

(e) Una política de difusión de información sobre las normas legales y la existencia de servicios de salud adecuados a ellas, que incluyeran campañas de información al público en general, los profesionales de la salud y autoridades de los sistemas sanitarios.

(f) La inclusión de los abortos legales en la definición de los deberes de cobertura de las empresas de medicina prepaga y las obras sociales a través de su incorporación al Plan Médico Obligatorio y otras normas relevantes. 
(g) El monitoreo y la evaluación de los servicios ofrecidos para su adecuación y mejora.

En un ambiente en el que nada de esto ha formado seriamente parte de una política de garantía de provisión de servicios de aborto legal a través de un modelo de causales como el del artículo 86 -reinterpretado a la luz de la Constitución y otras fuentes legales-, no resulta aceptable rechazar la adopción de una legislación más moderna como la que representa un sistema de plazos dentro o fuera de la legislación penal. Dejar vigente un régimen que ha mostrado la ineficacia e inseguridad jurídica del actual no sería parte del margen de consideración razonable para el poder legislativo hoy. Este reconocimiento del contexto deficitario en el que ha operado el artículo 86 del CPN torna más clara la necesidad de adoptar un régimen que limite el derecho penal y al hacerlo contribuya también a proveer más seguridad jurídica.

\section{Bibliografía}

Argibay, C., "Algunos problemas actuales en el acceso a los derechos sexuales y reproductivos", en Defensoría General de la Nación, Discriminación y Género: Las formas de la violencia, Buenos Aires, 2011.

Amnistía Argentina, "El acceso al aborto en Argentina: Una deuda pendiente", 2017. Informe disponible en https://amnistia.org.ar/wp-content/ uploads/delightful-downloads/2017/o9/EL-ACCESO-AL-ABORTO-EN-ARGENTINA-ENTREGAO3-FINAL.pdf

Ávila Santamaría, Ramiro, Acosta, A. \& Martínez, E., El neoconstitucionalismo transformador: el estado y el derecho en la Constitución de 2008, Ecuador, 2011.

Asociación por los Derechos Civiles, Acceso al aborto no punible en la Argentina. Estado de situación, ADC, 2015.

Barber, S. A. \& Fleming, J. E., Constitutional Interpretation, Oxford, 2007. Bergallo, P., "Cambio constitucional, reproducción y derechos", en Gargarella, R., La Constitución 2020, Buenos Aires, Siglo XXI Editores, 2011.

- "La liberalización del aborto: contextos, modelos regulatorios y argumentos para su debate", en Bergallo, P., Aborto y Justicia Reproductiva, Buenos Aires, Editores del Puerto, 2011. 
- "Las normas informales que regulan el aborto", en Cook, R., Erdman, J. \& Dickens, B., El aborto en el derecho transnacional: casos y controversias, Buenos Aires, Fondo de Cultura Económica, 2016.

- "Interpretando derechos: la otra legalización del aborto en América Latina”, en Casas, L. \& Lawson, D., Debates y reflexiones en torno a la despenalización del aborto en Chile, Universidad Diego Portales, 2016.

Brinks, D. \& Gauri, V., "Social rights constitutionalism: Negotiating the tension between the universal and the particular", en Annual Review of Law and Social Science 2015, 11:1, 289.

Cárdenas, E., López, A. \& De La Vega, L., "Aborto legal: Acceso desigualitario y criminalización selectiva", en Centro de Estudios Legales y Sociales (CELS), Derechos Humanos en la Argentina. Informe 2017, Buenos Aires, Siglo XXI Editores, 2018. Disponible en: https://www. cels.org.ar/web/capitulos/aborto-legal-acceso-desigualitario-y-criminalizacion-selectiva/.

Chiarotti, S., García Jurado, M. \& G. Schuster, "El embarazo forzado y el aborto terapéutico en el marco de los derechos humanos", en Foro por los Derechos Reproductivos, Buenos Aires, Foro por los Derechos Reproductivos, 1997.

Chiarotti, S., "El aborto en el marco de los derechos humanos. La situación en Argentina", en Checa, S. (comp.), Realidades y coyunturas del aborto: Entre el derecho y la necesidad, Buenos Aires, Paidós, 2006.

Defensoría General de la Nación, Informe: Causas penales por aborto propio en la Argentina, Buenos Aires, 2018. Disponible en: http:// www.mpd.gov.ar/index.php/noticias-feed/4258-segun-un-informede-la-defensoria-general-de-la-nacion-los-procesos-penales-por-eldelito-de-aborto-operan-en-si-mismos-como-castigo-y-las-condenas-son-la-excepcion.

De Sousa Santos, Boaventura, Refundación del Estado en América Latina: perspectivas desde una epistemología del Sur, Bogotá, Siglo del Hombre Editores, 2010.

Di Corleto, J., "Médicos, jueces y abortistas: Buenos Aires, 1940-1970", en Ramón Michel, A. \& Bergallo, P., La reproducción en cuestión, Buenos Aires, Eudeba, 2018.

Faerman, R., "Algunos debates constitucionales sobre el aborto", en Gargarella, R., Teoría y crítica del derecho constitucional, Buenos Aires, Abeledo-Perrot, 2009. 
Farrell, M., La ética del aborto y la eutanasia, Buenos Aires, Abeledo-Perrot, 1993.

Ferrante, M., "Sobre la permisividad del derecho penal argentino en casos de aborto", en Bergallo, P., Aborto y Justicia Reproductiva, Buenos Aires, Editores del Puerto, 2011.

Filippini, L., "Los abortos no punibles en la reforma constitucional de 1994", en Bergallo, P., Aborto y Justicia Reproductiva, Buenos Aires, Editores del Puerto, 2011.

Gebruers, C. \& Gherardi, N., El aborto legal en Argentina. La justicia después de la sentencia de la Corte Suprema de Justicia en el caso F., A. L, Buenos Aires, CEDES - ELA, 2015.

González Vélez, A. C. \& Bergallo, P., "Legal mobilization and the struggle to liberalize abortion laws in Latin America" (2018, mimeo).

Kramer, L., Constitucionalismo popular y control de constitucionalidad, Barcelona, Marcial Pons, 2009.

Lemaitre, J., "El sexo, las mujeres y el inicio de la vida en el constitucionalismo católico", en Cook, R., Erdman, J. \& Dickens, B., El aborto en el derecho transnacional: Casos y controversias, Buenos Aires, Fondo de Cultura Económica, 2016.

Monte, E., "La demanda por la liberalización del aborto en Argentina: de la politización de la sexualidad a los derechos reproductivos. Notas sobre el caso Portal de Belén”, en Ramón Michel, A. \& Bergallo, P., La reproducción en cuestión, Buenos Aires, Eudeba, 2018.

Morán Faúndes, J. M. \& Peñas de Fago, M. A., "La vida como política: La iglesia católica y las concepciones científicas y legales contrarias a la legalización del aborto", en Ramón Michel, A. \& Bergallo, P., La reproducción en cuestión, Buenos Aires, Eudeba, 2018.

Nino, C., "Algunas reflexiones sobre el tratamiento legal del aborto y la eutanasia”, en Bergallo, P., Aborto y Justicia Reproductiva, Buenos Aires, Editores del Puerto, 2011.

Rubio Marín, R., "Transferencias jurídicas sobre mujeres y fetos: un viaje del constitucionalismo del aborto alemán al portugués", en Ramón Michel, A. \& Bergallo, P., La reproducción en cuestión, Buenos Aires, Eudeba, 2018.

Siegel, R. \& Post, R., Constitucionalismo democrático: por una reconciliación entre Constitución y pueblo, Buenos Aires, Siglo XXI Editores, 2013 . 
Siegel, R., "La constitucionalización del aborto", en Cook, R., Erdman, J. \& Dickens, B., El aborto en el derecho transnacional: Casos y controversias, Buenos Aires, Fondo de Cultura Económica, 2016.

Vaggione, J. M., "La sexualidad en el mundo post secular. El activismo religioso y los derechos sexuales y reproductivos", en Gerlero, M. S., Derecho a la Sexualidad, Buenos Aires, 2009.

Von Bogdandy, A., "Ius constitutionale commune en América Latina: Una mirada a un constitucionalismo transformador", en Revista Derecho del Estado, 2015, 34: 3-50. 